\title{
FILOSOFÍA, HISTORIA DE LA FILOSOFÍA Y PENSAMIENTO ANTIGUO
}

\author{
Marcelo D. Boeri' \\ Universidad Católica de Chile
}

Recibido: 17.09.2018 - Aceptado: 01.04.2020

\begin{abstract}
RESUMEN
Después de que la realidad física comenzó a ser considerada matemáticamente y la concepción aristotélica del mundo fue abandonada, uno debería aceptar que el mundo que los antiguos griegos solían considerar ha desaparecido. También se podría decir que el mundo no es hoy lo que era hace algunas décadas. La revolución tecnológica y su progreso, la sofisticación de los métodos de comunicación, la aparición de nuevas enfermedades y calamidades, indican que nuestro mundo ya no es el que conocían los filósofos y científicos de las primeras décadas del siglo XX. Los filósofos antiguos no tuvieron que enfrentarse a este tipo de problemas. Sin embargo, tuvieron que tratar dificultades similares a las que los filósofos contemporáneos todavía se enfrentan. Mi afirmación en este artículo es que la filosofía antigua puede ser considerada como un pensamiento vivo y, por lo tanto, no como una "pieza arqueológica". Examinaré primero algunas formas posibles de considerar el estudio de la filosofía antigua; en segundo lugar, proporcionaré algunos ejemplos de problemas filosóficos planteados por los filósofos de la Antigüedad que han sido considerados seriamente por algunos distinguidos filósofos contemporáneos. Por último, haré algunas observaciones finales.
\end{abstract}

Palabras clave: Filosofía Antigua; historia de la filosofía; conocimiento; ignorancia

\begin{abstract}
After physical reality began to be considered mathematically, and the Aristotelian conception of the world was abandoned one should accept that the world the Ancient Greeks were in the habit of considering has disappeared. One might also say that the world is not today what it used to be some decades ago. The technological revolution and its progress, the sophistication of methods of communication, the appearance of new illnesses and calamities indicate that our world is no longer the world that was known by the philosophers and scientists of the first decades of the $20^{\text {th }}$ century. Ancient philosophers did not have to face these kinds of problems. My claim in this paper is that Ancient philosophy can be regarded as living thought and hence not as a "piece of archaeology". I shall examine first some possible ways of considering the study of Ancient philosophy. Secondly, I will provide some examples of philosophical problems posited by Ancient philosophers that have been considered seriously by some distinguished contemporary philosophers. Finally, I will give some concluding remarks.
\end{abstract}

Keywords: ancient Philosophy; history of philosophy; knowledge; ignorance

${ }^{1}$ mboeric@uc.cl 


\section{INTRODUCCIÓN: LOS FILÓSOFOS ANTIGUOS Y NOSOTROS}

En ocasiones, cuando uno está discutiendo o investigando una posición filosófica de un pensador de la Antigüedad, tiene que comenzar por hacer una especie de justificación de por qué tiene sentido estudiar, leer o comentar los textos de filósofos que vivieron hace más de dos milenios. A veces los estudiosos dedicados a investigar el pensamiento de los filósofos antiguos (de los cuales en algunos casos solo se conservan restos fragmentarios y, lo que es más grave, a veces ni siquiera se conserva una obra escrita por la sencilla razón de que dichas obras se perdieron por completo o porque el filósofo en cuestión nunca escribió una página) son vistos como individuos extraños, interesados en desentrañar lo que ha dicho alguien que ya fue "superado", o que habla de un mundo que ya no existe. Ambas cosas pueden ser ciertas en un determinado nivel de análisis: a veces puede decirse que un pensamiento "ha superado" a otro en la medida en que ha sido capaz de "resolver" un problema que había sido planteado como una verdadera aporía por un pensador anterior y que, hasta ese momento, no había encontrado una explicación satisfactoria, aunque para esto deba recurrir a premisas o esquemas conceptuales que son ajenos a las doctrinas filosóficas que se están discutiendo.

Por otro lado, en cierto sentido, también es correcto que el mundo del que hablaban los antiguos griegos ya no existe. Después de que la realidad física comenzó a ser concebida matemáticamente, se impuso esa idea y se abandonó la concepción aristotélica del mundo (para poner un ejemplo representativo que dominó las ideas cosmológicas y científicas durante siglos); después de los descubrimientos y avances científicos y tecnológicos de las últimas décadas, el mundo ya nunca más volvió a ser el mismo. Sin embargo, mutatis mutandis, uno también podría decir, creo, sin temor a caer en la exageración, que el mundo no es hoy lo que era hace cuatro o cinco décadas. La sorprendente revolución tecnológica y su permanente cambio, la velocidad y sofisticación de los medios de comunicación, pero también la aparición de nuevas enfermedades y calamidades (como el HIV, los nuevos síndromes -como la adicción al trabajo, que trae aparejado el agotamiento y el síndrome de fatiga crónica-, etc.), que aparentemente no existían hace cuatro o cinco décadas, indican que nuestro mundo no es ya el mundo que 
conocieron los filósofos y científicos de los primeros cincuenta años del siglo $\mathrm{XX}$.

Los filósofos antiguos no tuvieron este tipo de problemas; sin embargo, debieron enfrentar dificultades teóricas ( $\mathrm{y}$ a veces prácticas) semejantes a las que aún deben tratar los filósofos contemporáneos: ¿tenemos criterios confiables para distinguir entre lo que es correcto y lo que no lo es? ¿Es posible resolver el problema universalismo-particularismo? ¿Cuál es la naturaleza del conocimiento? Además de ser verdadera, ¿qué otras condiciones debe satisfacer una creencia para ser "conocimiento"? ¿Qué es la verdad y de cuántas maneras se entiende? Lo que quiero argumentar aquí es que la filosofía antigua puede considerarse como un pensamiento vivo, no como una "pieza arqueológica", y si esto es así, varios argumentos y perspectivas de los antiguos probablemente pueden incorporarse a la discusión contemporánea de algunas cuestiones. Tal vez esta afirmación podría considerarse una perogrullada; mi interés al señalar esto, sin embargo, se dirige especialmente a quienes, explícita o implícitamente, creen que no tiene sentido estudiar el pensamiento antiguo. ${ }^{2}$ En lo que sigue examinaré, primero, algunos modos posibles de considerar el estudio de la filosofía antigua. Luego, suministraré algunos ejemplos de problemas filosóficos planteados por los filósofos antiguos que han vuelto a ser considerados seriamente por algunos filósofos contemporáneos y, en algunos casos, incorporados a sus discusiones sistemáticas. Por último, presentaré algunas observaciones conclusivas.

\section{ALGUNOS MODOS POSIBLES DE ABORDAR EL ESTUDIO DEL PENSAMIENTO ANTIGUO}

Uno podría dar varias respuestas a la pregunta “¿por qué trabajar en filosofía antigua?". En vista de la brevedad, propongo analizar las siguientes cuatro: uno puede dedicarse al estudio de la filosofía antigua (i) por un interés puramente histórico; (ii) por una creencia arraigada que supone que, de algún modo, "la verdad" se encuentra esbozada (o incluso "establecida") en los pensadores del pasado, y cuanto más antiguos son éstos, más genuina parece ser esa verdad; (iii) porque siempre se nos ha dicho que si no nos ocupamos de los pensadores antiguos, no entenderemos a los pensadores contemporáneos; $y$, finalmente, (iv) porque los pensadores antiguos tienen algo que decirnos, tanto desde el punto de vista material (es decir, desde el punto

2 Dado que mi área de especialidad es la filosofía antigua, este tipo de sugerencia podría verse como una "defensa corporativa" de esta área de estudio. Aunque sin duda tengo un interés especial por el pensamiento antiguo, espero ser lo suficientemente persuasivo para mostrar que mi argumento va más allá de una mera defensa de ese tipo. 
de vista del contenido de los problemas que tratan) como desde la perspectiva un poco más formal que tiene que ver con sus maneras de pensar, sus recursos argumentativos, el modo de plantear los problemas y las estrategias propuestas para resolverlos. Si esta última respuesta es aceptable, sería posible incorporar a los pensadores antiguos a las discusiones contemporáneas y, si no a todas, al menos a algunas.

Las respuestas (i), (ii) y (iii) no me parecen persuasivas. Un filósofo, si en verdad lo fue, nunca tiene un interés puramente histórico, al menos para otro filósofo o para quien, sin ser filósofo en un sentido creativo estricto, pretende ejercitar su pensamiento en una dirección filosófica. Es cierto, sin embargo, que los pensadores antiguos también tienen un interés histórico. A mi juicio, la respuesta (ii) es la menos convincente, pues no creo en la verdad filosófica como algo cerrado y acabado, aunque, por cierto, cada filósofo a veces señala en qué dirección y sobre la base de qué presupuestos se encuentra la verdad dentro de su propio pensamiento que, por lo general, es creativo y no se limita a hacer una exégesis y exposición más o menos fiel de un pensador del pasado. ${ }^{3}$

Creo que la respuesta (iii) inicialmente puede ser atractiva, pero, a mi juicio, tampoco es completamente persuasiva. Uno puede encontrarse con personas que, aun ignorando buena parte de la historia de la filosofía, leen un texto filosófico y enseguida revelan tener una penetración filosófica muy peculiar, ${ }^{4}$ no solo respecto de su comprensión de lo que dice el texto, sino también para activar el propio pensamiento. No obstante, es desde luego cierto que el conocimiento del pasado filosófico (o al menos de parte de él) puede ser muy útil para hacer filosofía, para formar el propio pensamiento y para estimularlo o, simplemente, para evitar reinventar la rueda. La respuesta (iv) es la que personalmente encuentro más persuasiva y la que, filosóficamente, me resulta más estimulante. Los filósofos antiguos tienen algo que decirnos y a veces es posible incorporarlos al debate contemporáneo o

3 Uno podría sentirse tentado de hacer notar que siempre hay que enfrentar lo que podría denominarse "el problema de la legitimidad de los supuestos filosóficos", esto es, en qué medida es legítima la crítica que un filósofo $\mathrm{F}^{1}$ hace a otro filósofo $\mathrm{F}^{2}$, si $\mathrm{F}^{1}$ está tomando como punto de partida supuestos que no solo no serían aceptados por $\mathrm{F}^{2}$, sino que ni siquiera se le ocurrieron. No discutiré aquí este problema.

4 "Penetración" en el sentido de la capacidad que Aristóteles solía llamar ó $\gamma \chi$ ívot $\alpha$, "penetración o sagacidad para dar con el término medio en un tiempo que no supone

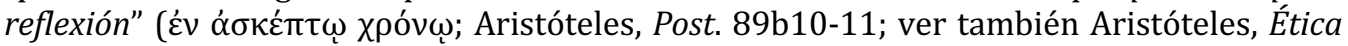
Nicomaquea 1142b5-6). Platón caracteriza la ó $\gamma \chi$ ívoı $\alpha$ como "una cierta agudeza del alma"

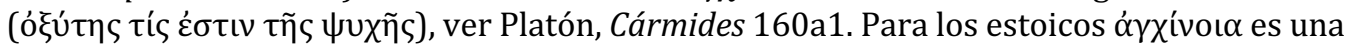

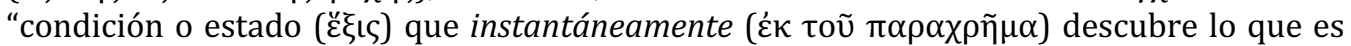

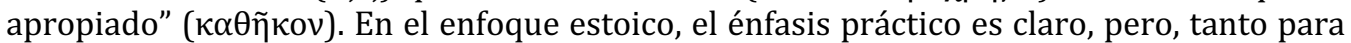
Aristóteles como para los estoicos, el detalle crucial es que esta capacidad describe la propia velocidad y agudeza en la comprensión de algo. 
de temas que se discuten en el contexto del pensamiento actual como cuestiones filosóficas genuinas. Desde el punto de vista de los contenidos, de los problemas que tratan, los pensadores antiguos (o al menos algunos de ellos) tienen algo que decirnos porque sus problemas, en cierto sentido, continúan siendo nuestros problemas: la relevancia de la percepción para entender cómo un sujeto se conecta con el mundo externo a él, el lenguaje, el pensamiento, la mente, el conocimiento, la felicidad, la amistad, la muerte, la justicia, la irracionalidad y racionalidad de la acción, la legitimidad o no de ciertos mecanismos argumentativos o de ciertos tipos de argumentos para explicar cierto tipo de cuestiones, etc.

Desde el punto de vista formal de los mecanismos argumentativos, los pensadores antiguos son también interesantes y una verdadera fuente de inspiración para muchos filósofos contemporáneos de las más variadas tendencias y tradiciones interpretativas. Los filósofos antiguos fueron sagaces argumentadores; un caso paradigmático de esto es el "Sócrates platónico" de los primeros diálogos o Aristóteles en sus demostraciones por el absurdo. También encontramos argumentos muy sofisticados sobre los temas más diversos en los estoicos (sobre todo en Crisipo y Posidonio), en el escéptico Sexto Empírico, en Epicuro o en Plotino (sólo para mencionar algunos de filósofos antiguos más significativos). Epicuro es muy ilustrativo de una cuestión que vale la pena considerar brevemente: una de sus tesis fundamentales es que es necesario someter a examen nuestras propias creencias cuando nos ponemos a investigar un tema. Entre otras cosas se esforzó por mostrar que las causas decisivas de la infelicidad humana residen en las creencias erróneas que tenemos sobre los dioses, la muerte, o sobre el falso valor que le otorgamos a cosas que, en realidad, no son bienes. ${ }^{5}$ La sugerencia de Epicuro es descartar todo aquello que, basado en creencias falsas o erróneas, perturba la vida humana. Aunque no coincidamos con las posiciones de Epicuro sobre ciertos temas específicos, su sugerencia de evitar fundamentar la evaluación de lo que consideramos bienes en creencias falsas ( $\mathrm{y}$, por ende, de intentar establecer cuáles son las creencias verdaderas y confiables) conserva toda su frescura y actualidad.

5 Véase Epicuro, Carta a Pítocles 85-86; Máximas Capitales 11-12; Carta a Meneceo 123-124. Este tema se relaciona con el "tetrafármaco" o "cuádruple remedio"

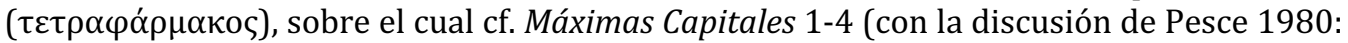
86-99) y Filodemo, Contra los sofistas IV 9-14. Sobre las propias creencias y los correspondientes estados afectivos conectados con dichas creencias, cf. la discusión de Elizabeth Asmis, Epicurus' Scientific Method. (Ithaca and London: Cornell University Press, 1984), 169-170. Ver también Diógenes de Enoanda, quien recomienda que toda elección y evitación deba basarse en un cálculo racional del placer o el dolor que la elección implica (cf. Diógenes de Enoanda NF 10 I 5-II 1.70 ed. Smith y Clay, 2001: 202-203). 


\section{FILOSOFAR CON LOS FILÓSOFOS ANTIGUOS}

A mi juicio, no hay duda de que algunos temas han ayudado a "rehabilitar" la filosofía antigua. En lo que sigue me limitaré a mencionar y comentar brevemente algunos de esos temas que, a mi juicio, han sido tratados seriamente por algunos filósofos contemporáneos teniendo en cuenta planteos y argumentos de los antiguos. No es extraño que algunos filósofos contemporáneos hayan examinado algunas teorías filosóficas antiguas, y que lo hayan hecho no meramente por su interés histórico, sino como problemas filosóficos por derecho propio. Esta afirmación no presupone ningún tipo de desvalorización de los historiadores de la filosofía o de la historia como un medio de conocimiento del pasado filosófico. De hecho, quien se dedica a la filosofía antigua o, en general, a la historia de la filosofía debe confiar no solo en los historiadores de la filosofía, sino también en los filólogos. La historia de la filosofía es, sin duda, una disciplina histórica; pero, podría argumentarse, es difícil hacer historia de la filosofía sin hacer al mismo tiempo filosofía. En efecto, cuando el historiador explica un pensador del pasado, está interpretando a dicho pensador (especialmente cuando el historiador explica filosóficamente el pensador en cuestión). Ciertamente, hay interpretaciones que son mejores o más confiables que otras. ${ }^{6}$ Es probable que esto sea así porque un gran filósofo no está sólo ni principalmente interesado en hacer historia de la filosofía, sino filosofía en un sentido constructivo. Como sugiere W. Wieland, ${ }^{7}$ uno hace tanto historia de la filosofía como filosofía cuando considera no solo las doctrinas representadas por los pensadores del pasado, sino también los temas que dichos filósofos discutieron y acerca de los que pensaron. Uno debe enmarcar el objeto de estudio (digamos la teoría aristotélica del tiempo) en términos de sus condiciones históricas, sociales y psicológicas. Sin embargo, si uno intenta extraer la riqueza filosófica del texto, no debe limitarse a investigar tales condiciones. Más bien, sobre la base de los propios intereses filosóficos, uno debe investigar si las doctrinas en juego alcanzan los objetos a los que dichos intereses dirigen su atención, sean o no los argumentos presentados por el autor, si sus puntos de partida son aceptables, etc. ${ }^{8}$

${ }^{6}$ No deja de ser interesante hacer notar que cuanto más filosófico es quien está haciendo historia de la filosofía, menos preciso es (o puede ser) desde un punto de vista histórico; dos ejemplos significativos de esto en la Antigüedad son Platón y Aristóteles. Desde luego que, en rigor, ellos no fueron historiadores de la filosofía, sino filósofos, pero a veces se refieren a los pensadores de su pasado en un sentido histórico.

7 Wolfgang Wieland, "La actualidad de la filosofía antigua”, Méthexis vol.1 №1 (1988): 5 ss.

${ }^{8}$ En un sentido similar, véase Yves Zarka, "The Ideology of Context: Uses and Abuses 
Siendo esto así, la solución puede ser hacer historia de la filosofía al "hacer filosofía", 9 y, por ende, uno podría admitir que un buen historiador de la filosofía debe tener un "toque filosófico" cuando trata un filósofo del pasado.

Mi discusión en lo que sigue en cierto modo irá en esa dirección: lo que me interesa destacar ahora es que algunos filósofos contemporáneos importantes han tomado seriamente la filosofía antigua como un pensamiento vivo, no como una pieza de arqueología. De hecho, cuando algunos filósofos contemporáneos se refieren a Platón o Aristóteles (solo para dar un ejemplo), toman en cuenta a tales filósofos como interlocutores serios, desafiantes y "actuales" en su esfuerzo por enfrentar y resolver ciertos problemas filosóficos.

\section{a) Platón y la llamada Teoría Tripartita del Conocimiento}

En epistemología contemporánea los filósofos hablan de la Teoría Tripartita del Conocimiento (TTC), ${ }^{10}$ una tradición que, según ellos, se remonta a Platón. ${ }^{11}$ De acuerdo con la TTC, deben satisfacerse tres condiciones para que pueda decirse que uno tiene conocimiento: la primera condición es la existencia de una creencia; a menos que uno crea algo, no puede conocerlo. Si uno cree algo (e.g. que "el conocimiento es percepción"), la creencia debe ser verdadera (esta es la segunda condición); por último, la creencia debe estar justificada. Si uno tiene una creencia y esa creencia está justificada, entonces ella cuenta como conocimiento. Si no lo está, la creencia no es conocimiento. $^{12}$

of Context in the Historiography of Philosophy." En Analytic Philosophy and History of Philosophy, de Tom Sorell y G.A.J. Rogers, (Oxford: Oxford University Press, 2005), 150.

${ }^{9}$ Una vez más, esta es una sugerencia de Zarka, quien a su vez sigue otra de Hegel. Zarka, "The Ideology of Context: Uses and Abuses of Context in the Historiography of Philosophy.", 151.

10 O "la concepción tripartita clásica del conocimiento". Jaegwon Kim, "What is 'naturalized epistemology'?" En Epistemology. An Anthology, de Ernest Sosa, Jaegwon Kim, Jeremy Fantl y Matthew McGrath (Malden-Oxford-Victoria: Blackwell Publishing, 2008), 539.

${ }^{11}$ Cf. Robert Shope, "Propositional Knowledge." En A Companion to Epistemology, de Jonathan Dancy, Ernest Sosa y Matthias Steup (Oxford: Blackwell Publishing Ltda, 2010), 644; Paul Moser, "Tripartite definition of knowledge." En A Companion to Epistemology, de Jonathan Dancy, Ernest Sosa y Matthias Steup, (Oxford: Blackwell Publishing Ltda, 2010), 771-772; Laurence Bonjour, Epistemology. Classic Problems and Contemporary Responses (Lanham-Boulder. New York-Toronto: Rowman \& Littlefield Publishers, 2010), 35.

${ }^{12}$ Sobre el "valor del conocimiento" (un enfoque que, de acuerdo con la epistemología contemporánea, también se remonta a Platón), ver Matthew Weiner, "Practical Reasoning and the Concept of Knowledge." En Epistemic Value, de Adrian Haddock, Alan Millar y Duncan Pritchard (Oxford: Oxford University Press, 2009), 163-182. El artículo de Weiner (como muchos otros en esta área de investigación) comienza por considerar la pregunta platónica de por qué el conocimiento es más valioso que la mera creencia u opinión, y argumenta que en la era "post-Gettier" la pregunta debe ser "por qué el conocimiento es 
Es bien conocido el hecho de que Platón distingue conocimiento

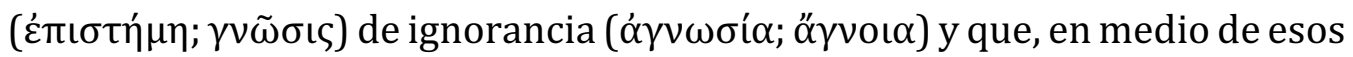
dos estados epistémicos (que entiende como "poderes" o "capacidades"), ubica la creencia u opinión $(\delta o ́ \xi \alpha)^{13}$. El conocimiento, argumenta Platón, es siempre verdadero y la ignorancia siempre falsa; la creencia es un estado intermedio (de la mente de uno: $\left.\delta \iota^{\alpha} v o เ \alpha\right)^{14}$ en la medida en que puede ser verdadera $y$ falsa (o, dicho más precisamente, verdadera $o$ falsa). ${ }^{15}$ Platón

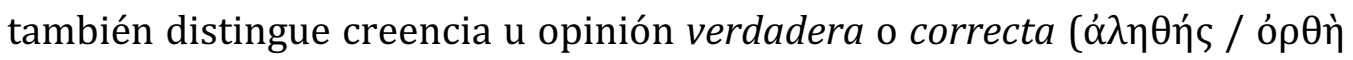
$\delta o ́ \xi \alpha)$ de conocimiento. ${ }^{16}$ El conocimiento, afirma, no puede ser una creencia verdadera ya que el conocimiento es estable, mientras que la opinión verdadera no lo es; además, mientras la persona que tiene conocimiento siempre dará en el blanco, el que tiene una opinión verdadera a veces da en el blanco, y otras veces no. ${ }^{17}$ Ahora bien, una opinión verdadera siempre es débil, ya que el que tiene una opinión verdadera sin conocimiento puede ser fácilmente persuadido a cambiar de opinión. ${ }^{18}$ La opinión verdadera consiste en juzgar las cosas correctamente, pero eso no requiere (al menos no necesa-

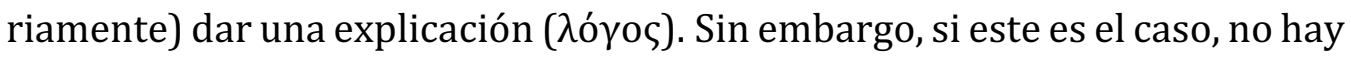
conocimiento. Entonces, la creencia verdadera no puede identificarse con el conocimiento, ya que el conocimiento es un estado psicológico que no puede carecer de explicación, un ingrediente decisivo en el conocimiento pues es el que le da estabilidad y firmeza a la creencia. ${ }^{19}$

Como indiqué antes, según la TTC, la creencia es la primera condición del conocimiento. A menos que uno crea algo, no puede saberlo. En el Teeteto (Teet.), después de proporcionar una larga y sofisticada argumentación en contra de la primera definición de conocimiento como percepción

más valioso que la mera creencia verdadera justificada". Como es obvio, la idea procede de la TTC, supuestamente basada en lo que Platón argumenta en el Menón y el Teeteto (entre otros diálogos).

13 Platón, República 479a9-11.

14 Platón, República 476d5-6.

15 Platón, República 476e-477c. Aquí sólo doy una descripción rápida del argumento de Platón. Para un análisis detallado del pasaje, véase Maurizio Migliori, Il Disordine ordinato. La filosofia dialettica di Platone I. Dialettica, metafisica e cosmología (Brescia: Morcelliana, 2013), 260-267.

16 Platón, Menón 97a-98c.

17 Platón, Menón 97c6-8.

18 Una postura que Platón continúa manteniendo en Timeo 51e, donde enfatiza que la verdadera opinión surge por medio de la persuasión y carece de explicación, es decir, es

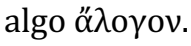

19 Platón, Simposio 202a; Fedón 76b; Teeteto 177b, 202c. En un sentido bastante platónico (que evoca República V) Aristóteles establece que lo que es objeto de

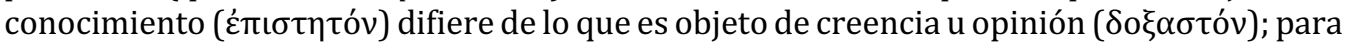
el contraste entre conocimiento y opinión, cf. Aristóteles, Analíticos Posteriores 75b21-26, 88b30-89a10; Ética Nicomaquea 1140b3-11141a8. 
( $\alpha$ ا̈ $\sigma \eta \eta \sigma \iota \varsigma$ ), el personaje Sócrates termina rechazando esa definición. ${ }^{20}$ Esto le permite a Platón salir del dominio de la experiencia perceptiva y entrar

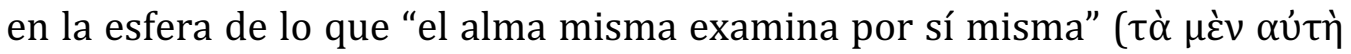

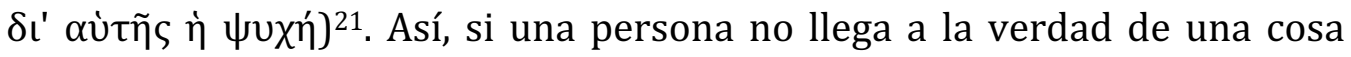
(donde "llegar a la verdad" de algo equivale a llegar a su ser o esencia:

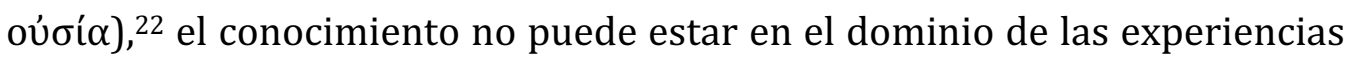

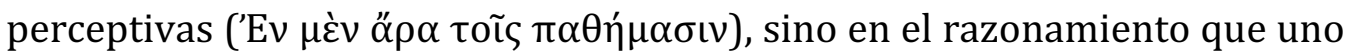

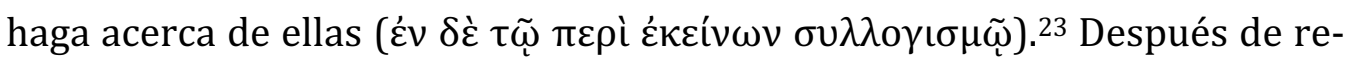
chazar la "definición perceptiva" de conocimiento, Platón está convencido de que los interlocutores han logrado "algún progreso" $(\pi \rho \circ \beta \varepsilon \beta \eta ́ \kappa \alpha \mu \varepsilon v)^{24}$, ya que no buscarán el conocimiento en el dominio de la percepción, sino en el ámbito de lo que el alma examina por y a través de sí misma. Lo que el

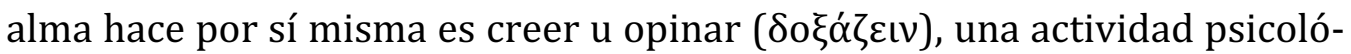
gica. ${ }^{25}$

Como los epistemólogos contemporáneos, Platón afirma que el conocimiento requiere tener una creencia. Sin embargo, por las razones antedichas, en la medida en que una creencia u opinión puede ser falsa, el conocimiento no puede ser cualquier tipo de creencia, sino una creencia verdadera. ${ }^{26}$ Por lo tanto, cualquier cosa que el conocimiento finalmente resulte ser, debe ser verdadero; sería contraintuitivo suponer que el conocimiento puede ser falso: "conocimiento falso" no es conocimiento en absoluto, de modo que, si el conocimiento es un tipo de creencia, debe ser una creencia verdadera. Esta segunda definición de conocimiento, como se sabe, también es rechazada. En vista de la brevedad, omito los argumentos de Platón para

${ }^{20}$ Entre esos argumentos, vale la pena resumir los siguientes: (i) en ciertos estados patológicos (como locura) o estados no patológicos pero en los que hay una falta de conciencia (como en los sueños), en los que quien percibe lo hace mal ( $\pi \alpha \rho \alpha \iota \sigma \theta \alpha \dot{\varepsilon} \varepsilon \theta \alpha$; Platón, Teeteto 157e3-4), la tesis de que el conocimiento es percepción resulta poco sólida. En efecto, podría haber percepciones falsas para el que percibe, de modo que resultará que las cosas no son como las que se le aparecen a cada uno, sino al contrario: nada es lo que (a)parece ser (Platón, Teeteto 157e-158a; el paréntesis en la "a" de "aparece" es para indicar el doble carácter -fenoménico y cognitivo- de la forma verbal $\varphi \alpha i ́ v \varepsilon \tau \alpha \iota)$. (ii) Si el conocimiento es percepción, y si uno conoce el objeto $x$ en el tiempo t y continúa conociendo tal objeto en el tiempo $t^{1}$, en la medida en que uno recuerda lo que sabía en $t$, parece seguirse que una persona a la que se le ha enseñado algo en el pasado y lo recuerda ahora, no lo sabe (en efecto, ya no lo está percibiendo más). (iii) Si percibir es lo mismo que saber, no percibir debe ser lo mismo que no saber. Parece seguirse entonces que el que no percibe no sabe, a pesar de que recuerda lo que le enseñaron y sabía. Esto, empero, es absurdo o, como dice

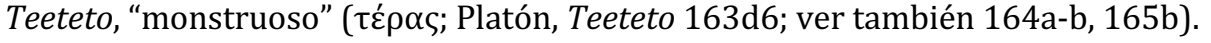

21 Platón, Teeteto 185 e6-7.

22 Platón, Teeteto $186 \mathrm{c} 6-\mathrm{d} 1$.

23 Platón, Teeteto $186 \mathrm{~d} 2-3$.

24 Platón, Teeteto 187 a3.

25 Platón, Teeteto 187 a8.

26 Platón, Teeteto 187b4-5. 
desestimar esta definición, de modo de poder centrarme brevemente en la última definición de conocimiento proporcionada por el personaje Teeteto:

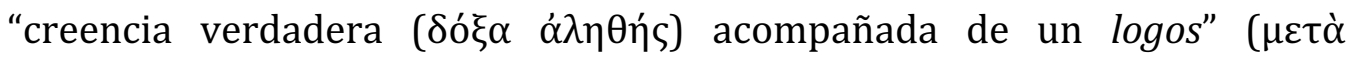

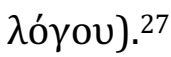

Es interesante notar que con cierta frecuencia se descubre que una creencia que se tenía por verdadera desde hace mucho tiempo resulta ser falsa. Si esto sucede (y desafortunadamente sucede a menudo), uno debe conceder que el objeto supuestamente conocido (que se describe en la creencia u opinión que se tenía por verdadera) en realidad no se conoce. Esto explica por qué el papel de la explicación o la justificación puede ser tan importante para el conocimiento. Si el sujeto $S$ sabe algo, no es suficiente que $S$ crea que es verdad: $S$ debe tener una razón o justificación para creerlo. Como sabemos, Platón también rechaza la tesis de que el conocimiento es una creencia verdadera más un lógos. Un estudioso de Platón podría argumentar que siempre es difícil saber si por lógos Platón quiere decir exactamente lo mismo que "justificación", tal como esta palabra se usa en la epistemología contemporánea. Sin embargo, en la medida en que en la filosofía contemporánea se asume que una "justificación epistémica" es la razón (o línea de razonamiento) que justifica la veracidad de una creencia o afirmación, parece que Platón no está demasiado lejos de lo que los filósofos contemporáneos suponen sobre esta materia.

Ahora bien, a pesar de lo que argumenta Platón en la sección final del Teet. (donde la definición de conocimiento como "creencia verdadera acompañada de un lógos" es rechazada), algunos epistemólogos contemporáneos exigen que la justificación epistémica sea uno de los ingredientes clave del conocimiento. Por supuesto, debe recordarse que, sin importar lo que Platón argumenta en el Teet., hay otros pasajes donde es claro que respalda la tesis de que uno tiene conocimiento sólo si puede "dar un logos" sobre lo que uno declara saber. ${ }^{28}$ Cualquiera que sea el caso, es evidente que los filósofos contemporáneos tomaron en serio la intuición de Platón de que los tres ingredientes claves del conocimiento son la creencia, la verdad y la explicación. Es cierto que algunos filósofos recientemente se han tomado grandes molestias para rechazar la TTC (o alguna versión de ella); ${ }^{29}$ pero esta manera de considerar el conocimiento continúa siendo parte de la discusión actual. Por las

\footnotetext{
27 Platón, Teeteto 202c7-8.

${ }^{28}$ Ver Platón, Menón 98a2-4; Protágoras 336b9-c1-2; Simposio 202a2-9; Fedón 76b4; República 531e3, 534b3-7.

${ }^{29}$ A modo de ejemplo, Timothy Williamson, Knowledge and its Limits. (Oxford: Oxford University Press, 2000), 3. El argumento de Williamson en contra de la TTC sostiene que, de acuerdo con la idea recibida, es posible conceptualizar los factores cuya conjunción con la creencia (i.e., "verdadera" y "justificada") es necesaria y suficiente para el conocimiento
} 
razones ya mencionadas, creo que este puede ser un buen ejemplo para mostrar que la epistemología de Platón sigue siendo una filosofía viva y no un fósil cuyo único interés es de carácter arqueológico.

\section{b) Platón, la filosofía de la mente contemporánea y la autoridad de la primera y tercera persona en el conocimiento}

En esta subsección mi atención se centrará en la forma en que Platón trató algunos otros temas filosóficos que le permitirían ser incorporado en algunos debates contemporáneos. Hoy en día la discusión acerca de la autoridad de la primera y tercera persona en el conocimiento sigue siendo un tema candente. El problema, como clásicamente fue tratado en la filosofía analítica, se remonta a las investigaciones de G. Ryle, quien argumentaba que cada individuo tiene un "acceso privilegiado" a sus estados mentales (una visión proto-cartesiana): "el autoconocimiento de la mente es superior en calidad [ ...] a su comprensión de otras cosas. Puedo dudar de la evidencia sensorial, pero no de la que obtengo a través de la conciencia o la introspección". ${ }^{30}$ Como ha señalado D. Davidson, las atribuciones en primera persona a menudo no se basan en ninguna evidencia. No obstante, una persona nunca (o difícilmente) deja de lado su convicción y afirmación de que tiene razón. ${ }^{31}$

Los puntos de vista de Ryle y Davidson evocan algunos problemas platónicos: la idea de Ryle de que cada persona tiene un acceso privilegiado a sus propios estados mentales es sugerida por Platón en un sorprendente pasaje del Teet., en el que argumenta así: (i) cuando lo que actúa sobre mí es

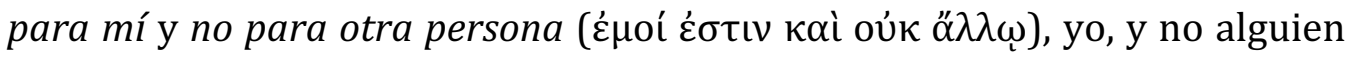
más, lo percibo. Por lo tanto, (ii) mi percepción es verdadera para mí -

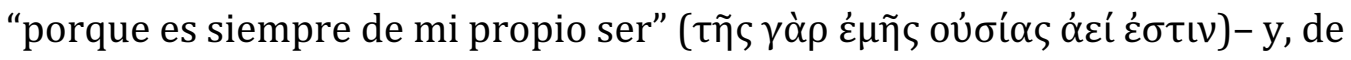
acuerdo con Protágoras, soy el juez de las cosas que son para mí, que son, y de las cosas que no son, que no son. ${ }^{32}$ Habitualmente este conocido pasaje

independientemente del conocimiento. La observación importante de Williamson es que, dado que el conocimiento implica la creencia (pero no viceversa), el conocimiento se toma como la conjunción de creencia con cualquier otro ingrediente que debe agregarse a la creencia para producir conocimiento, "la verdad y otras características más elusivas". La creencia, sin embargo, no puede ser conceptualmente anterior al conocimiento (por supuesto, el argumento de Williamson es mucho más sofisticado).

30 Gilbert Ryle, The Concept of Mind. (London and New York: Routledge, 2009), 137. Es decir, las percepciones sensoriales pueden ser confusas (e incluso erróneas), pero no la conciencia e introspección de tales percepciones. Ryle, The Concept of Mind, 4,145.

31 Donald Davidson, "First Person Authorithy." En Subjective, Intersubjective, Objective, de Donald Davidson (Oxford: Clarendon Press, 2001), 6.

32 Platón, Teeteto 160c4-9. Evito entrar en la discusión de los matices y sofisticaciones del argumento platónico. Una discusión filosóficamente potente puede verse 
del Teet. se tiene especialmente en cuenta para mostrar el punto de vista "subjetivista" de Protágoras, tal como lo interpreta Platón, pero también se puede leer como parte de la exploración de Platón acerca de qué es el conocimiento en términos perceptivos; un enfoque que finalmente rechaza, pero que al mismo tiempo toma en serio. La razón básica que tiene el "conocedor platónico" para pensar que hay un objeto extra-mental con tales y tales características (dulzura, por ejemplo) es que está teniendo una experiencia perceptiva de este tipo. El pasaje recién citado es parte de la sección conclusiva de un argumento que intenta probar que el estado en el que se encuentra la persona cuando tiene una experiencia perceptiva, es decisivo. Desde luego que no estoy suponiendo que en este pasaje del Teet. Platón sugiera explícitamente que tenemos "acceso seguro" a nuestros estados mentales; pero sí creo que es posible sostener que lo que está discutiendo aquí no es (radicalmente) diferente del problema del acceso privilegiado a nuestros estados mentales. ${ }^{33}$

La siguiente sección de Teet. 159a ss. puede ayudar a avalar aún mejor esta convicción: según Platón, (i) hay un número infinito de cosas activas y pasivas. Entonces, (ii) cuando algo se mezcla en un momento con una cosa y en un momento diferente con otra, no producirá el mismo efecto cada vez, sino diferentes efectos. Ahora bien, (iii) si esto se aplica a nosotros, uno podría notar que, por ejemplo, "Sócrates enfermo" y "Sócrates sano" son diferentes estados de la misma persona. Esto debería significar que, cuando alguno de los factores activos encuentre a Sócrates en un estado saludable, tratará con "un Sócrates" y, cuando lo encuentre enfermo, tratará con un "Sócrates diferente". En el ejemplo de Platón, si Sócrates bebe vino cuando

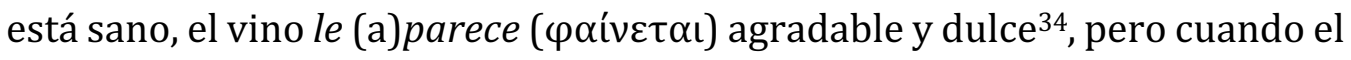
mismo factor activo (en el ejemplo, el vino) encuentra a Sócrates enfermo, le (a)parece diferente. Entonces, (iv) tanto Sócrates (enfermo) como el trago de vino generan cosas diferentes: una percepción de amargor en la lengua y un amargor que "llega a ser y se mueve" con respecto al vino. Sin embargo, observa Platón que el vino no es "amargor", sino "amargo", y la persona no

en Myles Burnyeat, "Idealism and Greek Philosophy." En Explorations in Ancient and Modern Philosophy, de Myles Burnyeat (Cambridge: Cambridge University Press, 2012), 251-254, quien ofrece un interesante contraste entre Platón y Berkeley. Véase también Franco Ferrari, Platone. Teeteto (Introduzione, traduzione e comment di Franco Ferrari) (Milano: BUR, 2001), 46-50.

${ }^{33}$ Se podría objetar que el uso que estoy haciendo de este y otros pasajes platónicos no toma en cuenta el contexto en que aparecen los textos, ideas y argumentos. Soy consciente de eso, pero este es el modo en que puede ponerse a dialogar a Platón con algunos enfoques contemporáneos y mostrar que él advirtió algunos problemas filosóficos que aún son familiares a los filósofos contemporáneos.

34 Platón, Teeteto 159c11-12. 


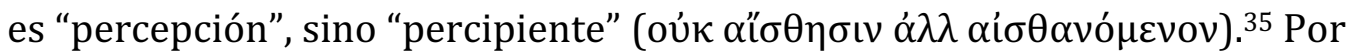
lo tanto, (v) el sujeto nunca se convertirá así en percipiente de ninguna otra cosa, ya que la percepción de otra cosa es otra percepción y lo convierte en un "percipiente cambiado". Sin embargo, lo que actúa sobre el sujeto, cuando se encuentra con otra persona ${ }^{36}$, no puede generar el mismo efecto, ya que tal efecto depende tanto del factor activo (el vino) como del estado en el que se encuentre la persona (sana o enferma). Finalmente, Platón hace notar (aunque no con estas palabras) que la percepción es un "elemento intencional", es decir, cuando el sujeto se convierte en perceptor, se vuelve perceptor de $\operatorname{algo}^{37}$, y cuando el objeto percibido se vuelve dulce o amargo, debe serlo para alguien. Entonces, tanto lo que percibe como lo que se percibe "son o llegan a ser el uno para el otro, porque la necesidad ata

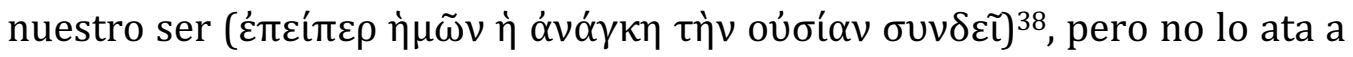
nada más, ni tampoco a nosotros mismos... estamos atados unos con otros, de donde se sigue que si uno dice que algo 'es' o 'llega a ser', tiene que decir

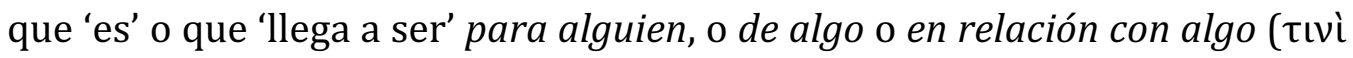

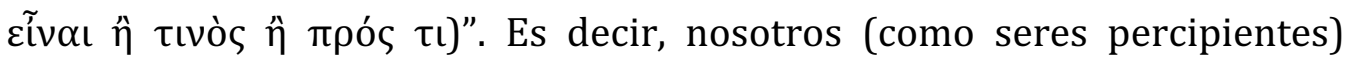
estamos en una relación recíproca con el objeto percibido. Por lo tanto, no se puede decir que algo es o llega a ser lo que llega a ser en sí mismo y por sí mismo.

Regresemos ahora a la tesis de Davidson según la cual las atribuciones en primera persona a menudo no se basan en ninguna evidencia. No pretendo sugerir que Davidson esté echando mano a o pensando en Platón cuando sostiene este tipo de opinión; sin embargo, su tesis tiene un trasfondo platónico que me propongo resumir brevemente en lo que sigue. La observación de Davidson de que una persona continúa afirmando que tiene razón, aunque su afirmación sea cuestionada o neutralizada por un argumento, recuerda el enfoque platónico de que nadie está dispuesto a creer que lo que cree es falso: ${ }^{39}$ cuando uno (honestamente) dice que $x$ es $p$, es porque realmente cree que $x$ es $p$ (es decir, cree que la proposición " $x$ es $p$ " es verdadera). Como observó Platón explícitamente, nadie admite que su propia creencia (ol̋́øıৎ; $\delta o ́ \xi \alpha$ ) sea falsa. ${ }^{40}$ De un modo semejante Davidson

35 Platón, Teeteto 159e4-5.

${ }^{36}$ En esta línea el griego es ambiguo ( $\alpha 2 \lambda \lambda \omega$ puede ser tanto neutro como masculino). Lo entiendo como masculino pues todo el argumento enfatiza el hecho de que el estado en que se encuentra el sujeto no es inocente en la explicación de la percepción. Así, la manera en que la persona está dispuesta en cierto modo determina el tipo de percepción que experimentará.

37 Platón, Teeteto $160 \mathrm{a}-\mathrm{b}$.

38 Platón, Teeteto 160b6-7.

39 Ver Platón, Alcibíades I113b8-11,117b-118a; Cármides 166d-167a; Sofista 228c-d.

40 Cf. Platón, Teeteto 171a1-b5, 200a 3-5. Para una perspectiva similar Davidson, "First Person Authorithy.", 4. 
nos recuerda que "desde tiempos de Descartes la epistemología se ha basado en el conocimiento de la primera persona; de este modo, habría que comenzar por considerar el problema del conocimiento como la cuestión del conocimiento de las propias sensaciones y pensamientos". ${ }^{41}$ Como Platón, Davidson propone revisar este modelo y sugiere que todo pensamiento proposicional exige la posesión del concepto de "verdad objetiva", y que este tipo de concepto sólo es accesible a quienes están comunicados con los demás. Esta es la razón por la cual las propias actitudes proposicionales son entendidas por otra persona solamente si uno puede atribuir tales actitudes a otro. Es en ese sentido, entonces, en el que Davidson argumenta que el enfoque de la tercera persona al lenguaje no es un mero ejercicio filosófico, de manera que el aspecto relevante es comprender cómo es posible llegar a entender el discurso y los pensamientos de otra persona, "pues esta capacidad es básica para nuestro sentido de un mundo independiente de nosotros mismos". Así, aun cuando el conocimiento de la tercera persona es crucial para todo nuestro conocimiento, es imposible independientemente del conocimiento de un mundo compartido en el que los demás desempeñan un papel importante. ${ }^{42}$

Una "versión platónica" de este enfoque aparece, mutatis mutandis, en el Alcibíades I"3: al intentar explicar el significado de la frase délfica "conócete a ti mismo", Platón sugiere que lo que la inscripción está diciendo es

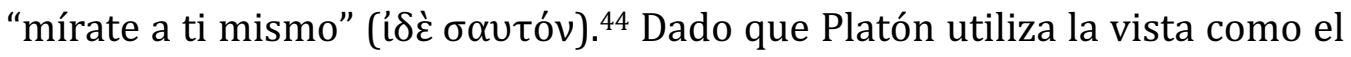
ejemplo adecuado para explicar la prescripción de "mirarse a sí mismo", uno puede sospechar que estará hablando de dos tipos de ver: el ver perceptivo y el no perceptivo (es decir, el modo en que los humanos eventualmente son capaces de ver con el "ojo del alma"). ${ }^{45}$ El ojo puede ver aquello que no se ve en un sentido perceptivo al mirar lo que se vería a sí mismo; esto es lo que sucede cuando uno mira el ojo de otra persona, y ese ojo funciona como una especie de espejo. Por eso es que uno puede mirar a alguien $\mathrm{y}$, al hacerlo, puede verse a uno mismo, siendo ese "sí mismo" su propia alma. Ahora bien,

41 Davidson, Donald. Subjective, Intersubjective, Objective. (Oxford: Clarendon Press, 2001), xvi. Véase Descartes, Reglas para la dirección del espíritu XII: "si Sócrates dice que duda de todo, se sigue necesariamente que al menos entiende (o "sabe": intelligit) esto: que duda"; AT X 421; mi traducción).

42 Donald Davidson, Problems of Rationality. (Oxford: Oxford University Press, 2004), xvi-xvii; "First Person Authorithy.", 17-18; "Deception and Division." En Problems of Rationality, de Donald Davidson (Oxford: Oxford University Press, 2004), 199-212, 204; "What Thought Requires." En Problems of Rationality, de Donald Davidson (Oxford: Oxford University Press, 2004), 143.

43 Platón, Alcibíades I 129a,132d-e.

$44132 \mathrm{~d} 6$.

45 Platón, República 533d2; Fedón 83a-b. Para un enfoque moderno (y naturalista) puede parecer extraño hablar acerca de un "ver no perceptivo"; pero para Platón advertir que " $p$ es el caso" es una actividad (inmaterial) del alma (también inmaterial). Para una discusión detallada de este pasaje del Alcibíades, cf. Napolitano Valditara 2007: 239-241. 
lo que se le aparece al que mira el ojo de otra persona, como en un espejo, es

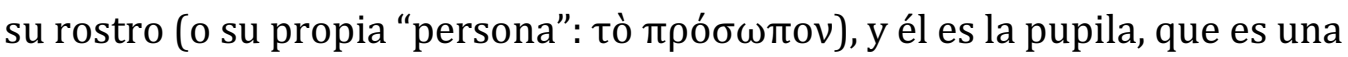
especie de imagen de quien está mirando. Entonces, si uno va a conocerse a sí mismo, debe mirar el alma de uno, pero a través de otra persona. Esta es la forma en que Platón presenta la cuestión del yo: lo que realmente soy es "alma". Entonces, si uno tiene la intención de conocerse a sí mismo, uno debe mirar el alma de uno; pero, al hacer esto, uno debe mirar primero el alma de otra persona. Es de esta manera que Platón introduce el tema del yo; además, sugiere que para conocerse a sí mismo uno necesita la mirada de la otra persona (la tercera persona). Este es un resumen burdo e incompleto del argumento, pero es suficiente en vista de mi propósito aquí.

Ahora bien, aunque uno generalmente vincula el "conócete a ti mismo" con el Sócrates de los primeros diálogos, ${ }^{46}$ el mandato vuelve a aparecer en un pasaje significativo del Filebo, sin duda un diálogo tardío. Sin embargo, el tema también lo discute Platón en un vívido pasaje de un "diálogo del período medio", como el Fedro (229b-230a), donde (el personaje) Sócrates dice que no tiene tiempo para cosas como las que dice la gente acerca de Boreas que raptó a Oritía, si todavía es incapaz de conocerse a sí mismo (i.e., si aún no se conoce a sí mismo, le parece ridículo ponerse a investigar cosas que le son ajenas; 229e6-230a1). Agrega que de hecho le parece ridículo (o "risible") investigar otros asuntos antes de haber entendido eso. Para entender el tema de la "ridiculez", es útil recurrir a un sorprendente pasaje del Filebo, donde la falta de autoconocimiento está vinculada con lo que es risi-

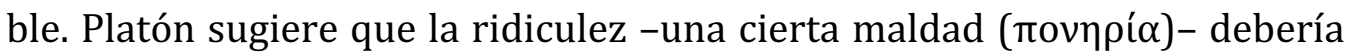
producir un estado afectivo que se opone a lo que recomienda el oráculo de Delfos. Si este no fuera el caso, la maldad, que es ignorancia, sería conocimiento (quod non). Quienes no se conocen a sí mismos experimentan dicho estado de ignorancia en tres aspectos: primero, con respecto al dinero (la gente cree que es más rica de lo que realmente es). En segundo lugar, las personas suelen pensar que son más fuertes o apuestas de lo que realmente son. Finalmente, el grupo más grande de personas cree que es más virtuoso, a pesar de que no lo es (48e9-10). Es con respecto a la sabiduría ( $\sigma 0 \varphi i^{\prime} \alpha$ ) que la mayoría de las personas está llena de rivalidad y de una sabiduría meramente ilusoria y falsa (49a2). ${ }^{47}$ Un estado afectivo ( $\left.\pi \alpha ́ \theta 0 \varsigma\right)$ como este (considerar como verdadero lo que en realidad no lo es) definitivamente es algo

46 Platón, Cármides 165a, 164e; Protágoras 343b. Véase también Jenofonte, Memorabilia IV 2, 24.

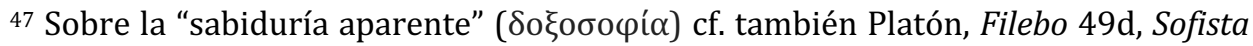
231b, y Fedro 275b2, donde Platón menciona el caso de aquellos que imaginan que han llegado a conocer mucho, aunque simplemente parecen ser sabios en vez de serlo realmente 
malo (49a4-5). Como es claro a partir de estos pasajes, Platón era consciente de que no disfrutamos de un acceso seguro a nuestros rasgos caracterológicos. Si esto es así, el conocimiento de uno mismo no podría ser simplemente el conocimiento de los propios estados mentales presentes, y esto debería tomarse como una restricción seria a la perspectiva de la primera persona en el conocimiento.

La conexión de todo el argumento con el examen de la ridiculez o de "lo que es ridículo" ( $\gamma \varepsilon \lambda o$ õov) ahora es más clara: la ridiculez es la condición opuesta al autoconocimiento, tal como lo prescribe el mandato délfico, ya que, si uno no se conoce a sí mismo, pero cree que se conoce, puede estar pensando erróneamente respecto de sí mismo. Esto puede considerarse como un caso de autoengaño, es decir, un caso en el que existe un desajuste entre la propia percepción de uno mismo y lo que efectivamente es el caso. ${ }^{48}$ En este tipo de situación, la posición privilegiada del conocimiento desde fuera de uno mismo (es decir, el punto de vista de la tercera persona) puede entenderse como la más razonable; presumiblemente esto es así porque le permite a uno abandonar una consideración "solipsista" de uno mismo. Una vez más, el problema básico es que nadie cree que lo que cree es falso. Sin embargo, las creencias pueden ser falsas, razón por la cual lo único que puede hacer que uno evite ser "ridículo" es el autoconocimiento. Entonces, ¿cómo puede uno salir del punto de vista de la primera persona, una perspectiva que, en el caso de alguien que no está dispuesto a escuchar las razones de los demás, puede adquirir un carácter dramáticamente solipsista? Una respuesta platónica razonable a esta pregunta es, sostengo, el diálogo

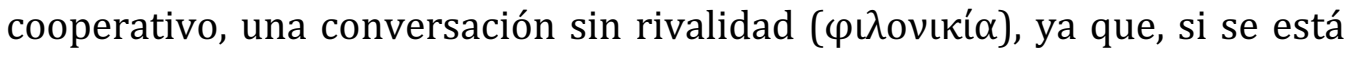
involucrado en una verdadera conversación filosófica, uno no está contendiendo por el amor a la victoria, de modo que la opinión de uno o del otro prevalezca. Los hablantes filosóficos deberían actuar juntos como aliados ( $\sigma u \mu \mu \alpha \chi \varepsilon \tilde{\imath} v$ ) por lo que es más verdadero. ${ }^{49}$

Permítaseme ser un poco anacrónico otra vez: creo que Platón habría estado de acuerdo con la postura contemporánea según la cual, si la objetividad es posible, debería basarse en la intersubjetividad, y esto es así no porque aquello en lo que la gente está de acuerdo sea necesariamente cierto,

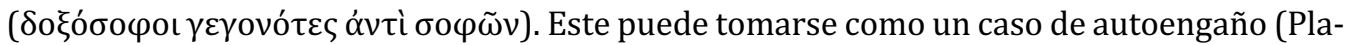

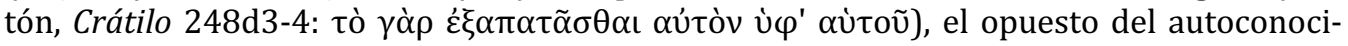
miento, "lo peor de todo".

${ }^{48}$ De cualquier modo, habría que admitir que el autoengaño siempre presupone alguna forma de conocimiento. Si no fuera así, no habrá autoengaño. Este "conocimiento", sin embargo, no puede ser el tipo de conocimiento que Sócrates busca.

49 Platón, Filebo 14b1-7. Según Platón, la investigación es una tarea compartida; consultar Crátilo 384c; Teeteto 151e; Sofista 218b y los otros pasajes citados supra, n. 46. 
sino porque la intersubjetividad depende de la interacción con el mundo.50 La intersubjetividad, observa Davidson, es la opinión de que la adquisición del conocimiento no debe entenderse como una "progresión" que va de lo subjetivo a lo objetivo. Tal adquisición emerge "holísticamente" de una manera interpersonal. Platón, por supuesto, no habla de "intersubjetividad"; ni siquiera tiene el término y, podría objetarse, probablemente no esté pensando en esto cuando sugiere que lo importante en una discusión filosófica es que los hablantes obtengan lo que es "más verdadero" como aliados en el marco de un esfuerzo compartido. Sin embargo, no hay duda de que Platón piensa que el requisito de colaboración en el diálogo es indispensable para obtener lo que es "más verdadero". ${ }^{51}$ Tal diálogo cooperativo siempre debe comenzar a partir de ciertos acuerdos. ${ }^{52}$ Sin duda, tales acuerdos se establecen de manera interpersonal por los hablantes mismos. Este es el sentido en el que creo que uno podría sospechar que tanto el punto de vista de la primera como de la tercera persona deben considerarse de manera complementaria: aunque parece ser cierto que la autoridad de la primera persona con respecto a los propios estados mentales es particularmente poderosa (como lo sugiere el pasaje del Teet. comentado antes), ${ }^{53}$ puede argumentarse que el punto de vista de la tercera persona podría contribuir a hacer que algunos contenidos de la propia mente sean más confiables (especialmente lo que uno piensa de uno mismo).

Como es claro, mi propósito no es sugerir que, al enfatizar la relevancia de la tercera persona como la condición para cualquier otro conocimiento, Davidson esté necesariamente desarrollando o apelando a lo que argumenta Platón. Mi observación es, más bien, que tanto Platón como Davidson comparten la idea de que, si la objetividad es posible, debe basarse en la "intersubjetividad". Sin duda, esta es una afirmación que en el caso de Davidson

50 Este es el enfoque de Davidson; véase "Indeterminism and Antirealism.", 83; "The Irreductibility of the Concept of the Self.", 91; "Rational Animals.", 105.

51 Es cierto, sin embargo, que, a diferencia de Platón, para Davidson lo que constituye "la verdad" es el logro del acuerdo en el diálogo más que el descubrimiento compartido de una verdad objetivamente existente. Véase Donald Davidson, Truth, Language and History. (Oxford: Oxford University Press, 2005).

52 Expresiones como "pongámonos de acuerdo también en lo siguiente" (Platón, Filebo 11d2. Véase también Filebo 37c, 40d, 60b) son comunes en Platón desde los diálogos tempranos. Los acuerdos entre los dos hablantes involucrados en el debate pueden entenderse como los puntos de partida de la conversación y como la coherencia del propio discurso (cf. Platón Gorgias 461b, 468e, 482d, 487e). Sin embargo, como observa Nikulin, un acuerdo absoluto entre los hablantes puede significar la muerte del diálogo; el desacuerdo estimula la conversación y, por ende, también el pensamiento. Dmitri Nikulin, Dialectic and Dialogue. (Stanford: Stanford University Press, 2010), 81, 99.

${ }^{53}$ Hay algunos estados psicológicos, como la sensación de dolor, que parecen ser irrefutables: ¿quién puede decirme que no estoy sintiendo lo que estoy sintiendo? 
no requiere ser probada; 54 es la conocida tesis davidsoniana de que la adquisición de conocimiento no debe entenderse como una "progresión" de lo subjetivo a lo objetivo. Por supuesto, Platón no habla de "intersubjetividad"; sin embargo, parece estar pensando en algo similar cuando enfatiza el requisito de un diálogo cooperativo para llegar a lo que es "realmente cierto", un diálogo cooperativo que siempre debe partir de algunos acuerdos básicos (homologíai) establecidos interpersonalmente.

\section{c) La ignorancia como virtud epistémica}

En esta última sub-sección discutiré algunas tesis y argumentos atribuidos al filósofo "Sócrates", i.e., el personaje de algunos diálogos tempranos de Platón (este es también el sentido en que he empleado el nombre "Sócrates" antes). ${ }^{55}$ A pesar de las muchas paradojas que podemos encontrar entre los diferentes diálogos, la imagen que Platón nos da de Sócrates es la de un pensador coherente. Como han señalado algunos connotados estudiosos de Platón, una de las razones de que el "Sócrates platónico" se haya convertido en el modelo de filósofo en que se convirtió radica en el hecho de que ha sido retratado como alguien para quien la coherencia del pensamiento, el discurso y la acción constituían una prioridad elevadísima. ${ }^{56}$

En lo que sigue me centraré en las nociones de conocimiento e ignorancia, dos conceptos que ya he tratado antes, pero que ahora consideraré desde una perspectiva diferente. La idea de proponer la ignorancia como una virtud epistémica y de atribuir este enfoque a Sócrates se inspira en una corriente relativamente reciente de la epistemología contemporánea: la tesis que le confiere una especial relevancia a la ignorancia en el marco de una teoría epistemológica. La epistemología como disciplina filosófica suele entenderse como "teoría del conocimiento", o como la teoría que explica aquello que es necesario para que efectivamente haya conocimiento. En ese tipo de teoría la confiabilidad y la justificación epistémicas suelen ser dos factores decisivos para sostener que una proposición $p$ es conocimiento. Tanto en las definiciones lexicográficas que encontramos en los diccionarios co-

54 Lo establece explícitamente varias veces en sus escritos. Ver Davidson, "Indeterminism and Antirealism.", 83; "The Irreductibility of the Concept of the Self.", 91; "Rational Animals.", 195.

55 Para la discusión del "problema de Sócrates" véase Charles Kahn, Plato and the Socratic Dialogue. The Philosophical Use of a Literary Form. (Cambridge: Cambridge University Press, 1996), 71-95.

${ }^{56}$ Cf. Terry Penner y Christopher Rowe, Plato's Lysis. (Cambridge: Cambridge University Press, 2015), 120, 202-203; Thomas Brickhouse y Nicholas Smith, Socratic Moral Psychology. (Cambridge: Cambridge University Press, 2010), 34. 
munes como las que se encuentran en el ámbito filosófico más o menos técnico, la ignorancia es lo opuesto al conocimiento; en ese sentido se define como "falta conocimiento" (esta es la supuesta "opinión estándar" de la ignorancia). ${ }^{57}$ Es en este sentido que puede argumentarse que conocimiento e ignorancia son términos complementarios: el sujeto $S$ ignora $p$, si y solo si $S$ no conoce $p .{ }^{58}$ Naturalmente, decir que la ignorancia es "falta o ausencia de conocimiento" es una caracterización apropiada, pero no dice mucho acerca de su papel, en caso de tener alguno, en el dominio epistemológico. Es por eso, se argumenta, que la cuestión de la ignorancia ha quedado relegada en el tratamiento técnico-filosófico de la epistemología ${ }^{59}$ y lo que esos enfoques recientes en los debates epistemológicos contemporáneos quieren hacer es mostrar el papel, central según algunos filósofos, de la ignorancia en las teorías que pretenden explicar qué es el conocimiento y cuáles son las condiciones que deben darse para que haya conocimiento. ${ }^{60}$ Lo que quiero sugerir es que varios de estos enfoques tienen conexión con aspectos sistemáticos que atribuimos a Sócrates y, si eso es así, creo que puede establecerse un diálogo fructífero entre el viejo Sócrates y los epistemólogos de las últimas décadas. Esos enfoques epistemológicos recientes han vuelto a valorar la idea de que la investigación de un problema también incluye un aspecto que apunta no a las creencias (al menos no directamente), sino a las preguntas. Este proceso de reconocimiento de nuestra propia ignorancia, argumentan algunos (como Sócrates hace más de dos milenios), no se encuentra separado de la investigación, sino que es parte esencial de ella. A tal punto es relevante que, si se ignora la "fase interrogativa" de la investigación, la creencia puede no ser el único o mejor objetivo del estadio posterior o conclusivo de la pesquisa. ${ }^{61}$

Es claro que Sócrates (o la versión que Platón nos da de él) advirtió la relevancia del autoexamen y la interrogación; también advirtió claramente que la ignorancia asociada al autoexamen puede ser una virtud epistémica,

57 Pierre Le Morvan, y Rik Peels. "The Nature of Ignorance; Two Views.” En The Epistemic Dimensions of Ignorance, de Rik Peels y Martikn Blaauw (Cambridge: Cambridge University Press, 2016).

58 Alvin Goldman y Erik Olsson. "Reliabilism and the Value of Knowledge." En Epistemic Value, de Adrian Haddock, Alan Millar y Duncan Pritchard (Oxford: Oxford University Press, 2009), 19-20.

59 Ver Rik Peels y Martikn Blaauw. "Introduction." En The Epistemic Dimensions of Ignorance, de Rik Peels y Martikn Blaauw (Cambridge: Cambridge University Press, 2016.), 2-3.

60 Ver Duncan Pritchard, "Ignorance and Epistemic Value." En The Epistemic Dimensions of Ignorance, de Rik Peels y Martikn Blaauw (Cambridge: Cambridge University Press, 2016), 132. El autor señala que, aunque la ignorancia es una posición epistémica negativa, de ello no se sigue que sea una posición epistémica disvaliosa.

61 Ward Jones, "The Good and Motivation of Believing." En Epistemic Value, de Adrian Haddock, Alan Millar y Duncan Pritchard (Oxford: Oxford University Press, 2009), 140. 
no un vicio. Además, es bastante obvio que el "problema del conocimiento" (probablemente del conocimiento "moral") fue un tema central en Sócrates. Explicaré a continuación la manera en que entiendo la "ignorancia socrática" (IS); como diferente de lo que llamaré la "ignorancia contumaz" (IC, la ignorancia propia del necio) y el papel que, creo, desempeña en la filosofía socrática. Si la IS desempeña un papel importante en el modo en que Sócrates filosofa y, por ende, es diferente de quien se rehúsa a entender, dicha ignorancia no puede ser (al menos no únicamente ni en todos los casos) ignorancia en el sentido de carencia de ciertos contenidos cognitivos específicos: un sujeto $S$ puede poseer un determinado conjunto de contenidos cognitivos, ser competente en esa área profesional y, no obstante, su estado mental puede ser el de la IC. En ese contexto la IC puede entenderse como la disposición a no entender una explicación o argumento. Es en este trasfondo en el que puede entenderse mejor, sugiero, el dictum socrático, según el cual la más terrible ignorancia es creer saber lo que en realidad no se sabe, una tesis que aparece por primera vez en los "diálogos socráticos" y que se mantiene intacta hasta los diálogos tardíos.

Sócrates dice que "sabe consigo mismo", que "es consciente de" ( $\sigma u ́ v o เ \delta \alpha$ ) que no es sabio en absoluto; 62 si no sabe, debe acudir a los expertos, o a los que dicen serlo (i.e., a los "supuestos expertos") en determinadas áreas del saber. Si uno no se considera a sí mismo un experto, debe buscar a quien posee una competencia cognitiva (o a quien dice poseerla), alguien que legítimamente sepa lo que uno ignora y desea saber. Si esa persona efectivamente sabe y si uno tiene alguna evidencia de que dicha persona no solo cree saber, sino que además sabe, puede considerar a ese individuo como un "superior epistémico". Si uno, que es ignorante en un área profesional específica, advierte que tiene un desacuerdo con un experto respecto de un tema particular, debería adoptar el punto de vista del experto. Sin embargo, ¿qué evidencia puede tener uno, siendo un lego, de que otra persona, que declara ser competente en un área específica del saber, efectivamente sabe lo que dice saber? Este es un problema advertido por Sócrates: en Cármides 170e23 (y como conclusión de un largo argumento), Sócrates sostiene que uno puede no ser capaz "de distinguir a quien finge que es médico, aunque no lo es, de quien en realidad lo es, ni a ningún otro entre quienes tienen conocimiento de los que no lo tienen". 63 El problema que todos tenemos como legos es cómo evaluar a los supuestos expertos. En el contexto de este diálogo Sócrates argumenta que si la sensatez ( $\sigma \omega \varphi \rho o \sigma u ́ v \eta)$, una forma de conocimiento, nos gobernara, uno haría todo de acuerdo con los diferentes tipos

62 Platón, Apología 21b4-5.

63 Platón, Cármides 170d-e. 
de conocimiento, de modo que nadie que diga que es un piloto, un médico o un general podría fingir que lo es sin serlo. ${ }^{64}$ Las personas vivirían con conocimiento y no serían presas fáciles del engaño. Hay un sentido en que, cuando efectivamente confiamos en un experto, nuestra confianza es ciega, especialmente si somos completamente ignorantes respecto del tema. Sin embargo, Sócrates tiene otro recurso para examinar a los supuestos expertos: someterlos a sus implacables preguntas.

Si uno advierte que otro es más competente que uno mismo en un área específica del saber, lo que (en buena fe) debería hacer ante esa persona (que es su superior epistémico) es cambiar de idea, al menos si tiene alguna razón para sospechar que, después de la explicación proporcionada por el experto, lo que uno piensa puede ser falso: si mi médico me dice que mi estilo de vida es dañino para mí (bebo y fumo en exceso, no hago suficiente ejercicio y no cuido mi alimentación) y reconozco que mi médico sabe más que yo acerca de mi salud o del modo de conservarla, debo cambiar de idea y hacer el esfuerzo por internalizar las (probablemente sensatas) indicaciones del médico en mis prácticas vitales habituales. "Internalizar" las indicaciones del médico significa aquí reconocer el contenido teórico de dichas indicaciones e incorporar tal contenido a la acción. ${ }^{65}$ Sin embargo, el Sócrates de algunos diálogos platónicos muestra con cierta frecuencia el hecho de que las personas pueden ser particularmente resistentes a cambiar de idea, incluso cuando alguien les muestra que están o pueden estar en el error (parece que eso es algo particularmente poderoso en la psique humana, algo que Sócrates advirtió con claridad). Hay un pasaje platónico muy claro a este respecto que describe muy bien este hecho. El personaje Filebo dice en el diálogo homónimo: "me parece y me seguirá pareciendo ( que el placer vence por completo; en cuanto a ti, Protarco, tú mismo sabrás". ${ }^{66}$ Como he sugerido en otro lado, ${ }^{67}$ este tipo de actitud recalcitrante justifica que Platón escoja dejar fuera del debate a Filebo. Como es obvio, el personaje Filebo es una construcción de Platón, cuya intención tal vez sea describir el carácter de quien prefiere conservar dogmáticamente sus creencias y posiciones sin someterlas al examen de la discusión dialógica. ${ }^{68}$ La actitud de persistir en la creencia que se tiene respecto de algo y el

\footnotetext{
64 Platón, Cármides 173a-b.

65 Para un enfoque similar en Platón, pero en un contexto diferente, cf. Teet. 178c-d.

66 Platón, Filebo 12a7-8.

67 Boeri 2016: 369-370.

68 O, como sugiere entender Gadamer (1999:187) la actitud de Filebo, este renuncia a oponer su tesis valiéndose de la argumentación lógica, la que siempre presupone recibir la crítica y ser, potencialmente, refutado. Sobre la relevancia que también tiene el método dialógico (entendido como método de refutación) en Davidson, véase Davidson (2005: 252254) y Natali (2007: 113-43, en especial 139-140).
} 
desinterés por someterla a prueba revela por parte de Filebo una actitud muy poco filosófica; eso es ignorancia en el sentido IC. En cambio, para Platón y, en general, para el Sócrates platónico desde los primeros diálogos hasta los diálogos tardíos (como el Teeteto y el Sofista), la sana actitud filosófica y de compromiso con la discusión dialógica presupone ser capaz de revisar las propias creencias $\mathrm{y}$, de ser necesario, modificarlas. Las creencias filosóficas son, en opinión de Platón, susceptibles de ser modificadas por un argumento. ${ }^{69}$ La refutación no debe entenderse como una afrenta, sino como una especie de "correctivo" del error, por así decir, y es lo que, finalmente, garantiza que uno sea capaz de revisar su propia opinión y, si es necesario, corregirla. ${ }^{70}$ Sócrates ni siquiera está dispuesto a aceptar sin examen el testimonio del oráculo de Delfos respecto de su propia sabiduría. Cuando en la Apología de Sócrates el oráculo le dice a Querefonte que ninguno es "más sabio" que Sócrates ${ }^{71}$ y que este es "sapientísimo",72 Sócrates tiene dudas y no acepta el dictum del oráculo sin investigarlo. Hay un sentido en el que se podría pensar que Sócrates duda del oráculo, que resulta ser el experto y su superior epistémico, cuya infalibilidad apenas puede ponerse en duda: después de todo, el oráculo es el vocero de Apolo y, desde luego, los dioses, si efectivamente lo son, no se equivocan ni mienten. Si Apolo dice que Sócrates es sapientísimo, debe ser verdad lo que dice. Otro modo de entender esto es argumentar no que Sócrates es escéptico acerca de lo que el dios le dice a Querefonte ("Sócrates es sapientísimo"), sino que está intentando entender el significado de lo que dice el dios. ${ }^{73}$ Me gustaría sugerir que no es que Sócrates tenga dudas acerca de lo que el dios dice a través del oráculo (aunque está seguro de que él no es sabio), sino que no logra entender qué quiere decir el dios cuando afirma que él es sapientísimo. Sin embargo, se podría pensar que en cierto sentido duda de lo que dice el dios, pero también duda de lo que cree saber (eso es IS), pues su creencia se opone a la del dios. Sócrates se pone a investigar lo que dice Apolo, pero, a la vez, duda de sí mismo porque está seguro de que lo que el dios dice es verdad. Esto no es lo mismo que argumentar que Sócrates quiere probar que el oráculo está equivocado y que, por ende, debe ser refutado. Solamente

${ }^{69}$ Según el Sócrates platónico, "la investigación es conjunta” (Platón, Menón 80d3-4:

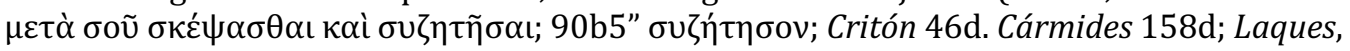
187d; Protágoras 330b. La misma idea, sin embargo, se encuentra en el Platón de los diálogos del período medio y de vejez (véanse los pasajes citados supra, n.30).

70 Cf. Platón, Gorgias, 458a2-b1. Véase también Platón, Eutidemo 295a; Sofista 230b-

e.

71 Platón, Apología 21a6-7.

72 Platón, Apología 21b5-6.

73 Platón, Apología 21b7. Sobre este detalle puede consultarse Thomas Brickhouse y Nicholas Smith, Socratic Moral Psychology (Cambridge: Cambridge University Press, 2010), 77. 
puede estar examinando lo que el oráculo dice de modo de intentar comprenderlo; y esto es así, sugiero, porque Sócrates entiende la afirmación del

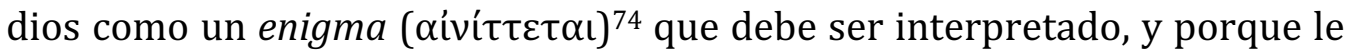
parece que otros son más "sabios" (o competentes). Sócrates entonces no está negando la autoridad de lo que el dios dice acerca de él, sino que parece estar dudando de sí mismo. Si Sócrates efectivamente "está seguro" de que él no es sabio, ${ }^{75}$ no tiene dudas acerca de su ignorancia. Si eso es así, su ignorancia no puede identificarse con la típica ignorancia contumaz (IC) de quien cree saber lo que en realidad no sabe y quedarse cómodamente instalado en esa creencia. ${ }^{76}$

A diferencia de la IC, la IS tiene un carácter activo que impulsa a la investigación. Finalmente, luego de interrogar a los supuestos expertos (políticos, poetas, artesanos, con el fin de "refutar, si es posible", es decir, de "examinar" -غ́र $\varepsilon^{\prime} \gamma \xi \omega \nu$ - el dictum del dios) Sócrates advierte que entiende por qué sí es "sapientísimo", como afirma el dios: lo que ocurre es que ha logrado compatibilizar lo que dice el dios ("Sócrates es sapientísimo") con lo que él cree de sí mismo (que es ignorante) mediante una interpretación de la afirmación délfica: "soy sapientísimo porque no creo saber lo que no sé". Sin embargo, también comprende que su saber no reside en el hecho de poseer un saber positivo (en el sentido de la posesión de un conocimiento específico), sino en que conoce los límites de su propio saber. Cuando Sócrates comienza a poner en práctica su método para examinar si quien dice ser un experto en algo efectivamente lo es, ${ }^{77}$ comienza por subrayar que se dirigió a "uno de los que parecían ser sabios", el político (probablemente, en el sentido de "uno de los que era tenido por sabio" o "que tenía reputación de sabio"). ${ }^{78}$ Luego de someterlo a examen, Sócrates concluye que él mismo es más sabio que el político con quien está conversando porque, aunque ninguno de los dos sabe nada "noble ni bueno", el político cree que sabe algo, aunque en rigor no lo sabe. Como recuerda Sócrates, le pareció que no solo muchas otras personas creían que el político era sabio, sino especialmente él mismo. Seguramente este énfasis no es trivial, porque describe el estado psicológico del individuo que no tiene dudas respecto de su propio saber. Él, Sócrates, en cambio, no sabe, pero tampoco cree saber, ${ }^{79}$ y concluye que le

${ }_{74}$ Platón, Apología 21b4.

75 Platón, Apología 21b4-5.

76 Desde una perspectiva contemporánea esto puede leerse como lo que los epistemólogos llaman "humildad epistémica" (Pritchard, "Ignorance and Epistemic Value").

77 Platón, Apología 21c3.

${ }^{78}$ Platón, Apología $21 \mathrm{~b} 8$.

79 Platón, Apología 21d4-7. 
pareció que era más sabio que el político "por un pequeño detalle" ( $\sigma \mu \iota \kappa \rho \tilde{\omega}$ $\tau(v \iota),{ }^{80}$ i.e., por no creer saber lo que en realidad no sabía. ${ }^{81}$

En la sección 21b-d de la Apología que he discutido antes, el tipo de conocimiento o saber que Sócrates descubre en sí mismo no es un conocimiento que se refiera de un modo claro o directo a un cierto Dominio Cognitivo ( $D C O$ ), sino la "consciencia" que declara poseer desde el comienzo del pasaje de que no es sabio en lo más mínimo. Más adelante contrastará ese conocimiento con la IC que vuelve a mencionar en Apología 29b1-2 ("¿no es

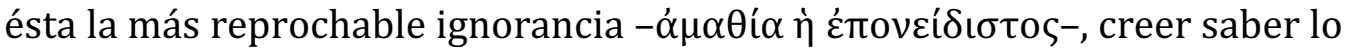
que uno no sabe?") y a la que regresa con peculiar énfasis y dramatismo en el Sofista, 82 un diálogo seguramente muy tardío en la producción filosófica de Platón, pero que mantiene intacta una poderosa idea de un diálogo temprano como la Apología. Creer que uno conoce sólo lo que realmente conoce, también es "conocimiento". Un poco antes en el texto se había estado hablando de la ignorancia como de una cierta deficiencia en el alma; el Visitante concluye que es "un enorme y difícil tipo de ignorancia" creer que uno sabe si, en realidad, no sabe. ${ }^{83}$ Creer que uno sabe lo que realmente sabe, sugiero, es un estado peculiar del alma que no puede entenderse en términos proposicionales. En realidad, creo, es "pre-proposicional" y puede entenderse como la condición decisiva para permitir la discusión dialéctica (que obviamente se da en términos proposicionales). Ese tipo de afirmación

80 Platón, Apología 21d6. Como sabemos, cada vez que Platón introduce la expresión "pequeño" o "insignificante" para referirse a algo que está discutiendo o que está por discutir, lo que viene a continuación no es ni pequeño ni insignificante. Se trata de un giro un poco irónico que, por lo general, el personaje Sócrates utiliza para introducir aspectos que son relevantes para un argumento o para una nueva explicación. Uno podría pensar que, si Sócrates no tiene una intención irónica al hacer uso de este recurso, lo utiliza para ganar la confianza del interlocutor y, pedagógicamente, allanarle el camino en una difícil cuestión como la que se está discutiendo. Un uso muy parecido de este recurso puede verse en el Teeteto, donde el tema que será objeto principal de discusión surge casi inmediatamente a partir de la perplejidad (árтóí $\alpha$ ) que Sócrates dice experimentar sobre un asunto en particular. La perplejidad socrática, que desempeña tan importante función

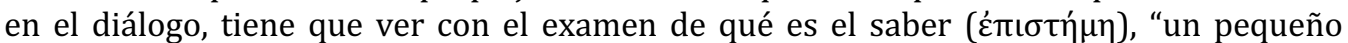

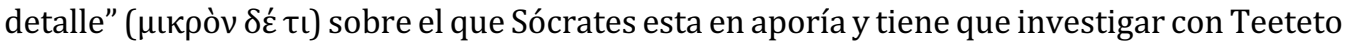
y con el resto de los presentes (véase, Platón, Teeteto, 145d6-7).

${ }^{81} \mathrm{La}$ verdadera ignorancia es creer saber lo que en realidad uno no sabe; Platón, Apología de Sócrates 41b; Alcibíades I117d (véase también Teeteto 201c; Sofista 229c).

82 Conocer aquellas cosas que solamente uno conoce y nada más, ese es el mejor y más sabio de los estados en que uno puede encontrarse (Platón, Sofista 230c8-d5).

83 Platón, Sofista 229c1-5. 
y de actitud general es frecuente en los diálogos iniciales de Platón, comenzando por la Apología, pasando por el Cármides, el Eutidemo, el Menón, el Gorgias $^{84}$ y algún otro pasaje de la producción temprana de Platón. ${ }^{85}$

Me parece entonces que la IC, no la IS, es equivalente a estupidez, la misma que impide que una persona sea capaz de comprender un argumento o explicación, cuando ese argumento o explicación es una mejor razón. Eso no significa necesariamente que la persona no entienda el argumento, sino que su obstinación, su porfía, le impide comprender. Quien se encuentra en ese estado psicológico no es capaz de dudar de sí mismo: contra la ignorancia (entendida como estupidez) ningún argumento es persuasivo o, en realidad, no hay argumento posible. Se trata de un estado de ignorancia que se opone radicalmente al socrático.

\section{OBSERVACIONES FINALES}

Comencé la sub-sección anterior haciendo notar que algunos aspectos de la llamada "epistemología de la ignorancia" pueden tener alguna conexión con ciertas observaciones sistemáticas de los “diálogos socráticos” (y no tan socráticos) de Platón. Aunque los filósofos contemporáneos muestran que la ignorancia suele entenderse como algo disvalioso en las discusiones epistemológicas (y por eso ha quedado relegada en dichas discusiones), hay un sentido en el que la investigación de un problema o el esfuerzo por tratar de entender una dificultad apunta no a las creencias, sino a las preguntas. Si la actitud inquisitiva puede entenderse como un combustible poderoso en la búsqueda del conocimiento, uno podría albergar fundadas esperanzas para pensar que la actitud socrática (que parte de la ignorancia) en la búsqueda del conocimiento es relevante. Desde luego que la búsqueda socrática del autoconocimiento no se limita a la mera introspección de los propios estados mentales: el alma socrática no puede ser completamente asimilada a la "mente" de la que hablan los filósofos de la mente contemporáneos. La 廿uxń socrático-platónica también es una entidad capaz de determinar la calidad moral de la persona.

Finalmente, aunque sí creo que pueden establecerse vínculos entre Sócrates y la "epistemología contemporánea de la ignorancia" o, dicho de una

84 Platón, Eutidemo 305c-d; Menón 84a; Gorgias 509a.

85 El pasaje de Menón 84a es particularmente interesante, pues ahí Platón muestra los dos momentos de la conversación filosófica y el estado psicológico del interrogado: antes de la conversación, el esclavo ignoraba qué era una superficie de ocho pies ("aún no lo sabe", recuerda Sócrates en Platón, Menón 84a5-6), pero "creía saberlo y respondía con

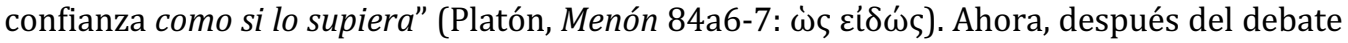
filosófico, está en aporía, en dificultad, está perplejo y, aunque no sabe, tampoco cree saber. 
manera más general, entre los filósofos antiguos y los contemporáneos, también hay diferencias significativas. Cuando los epistemólogos contemporáneos quieren mostrar que la ignorancia puede ser algo epistémicamente valioso, a veces recurren a ejemplos para señalar que hay casos en los que el conocimiento puede ser epistémicamente disvalioso: supongamos que una persona llega a saber que es adoptada; eso puede producir una enorme infelicidad, a punto tal que la persona hubiese preferido no enterarse nunca de eso. ${ }^{86}$ Ese tipo de ejemplo seguramente no se ve muy socrático: el conocimiento en general y el "conocimiento moral" (en el que Sócrates parece haber estado especialmente interesado) nunca puede ser disvalioso. Sin embargo, lo que el enfoque que pretende fortalecer la dimensión epistémica de la ignorancia se propone mostrar es que, si la ignorancia es ausencia de conocimiento (la "opinión estándar") y el conocimiento a veces puede ser disvalioso (un énfasis que, como he dicho, Sócrates no pondría), se sigue que la ignorancia a veces puede ser valiosa. Ahora bien, claro, ni este tipo de ejemplo ni la tesis de que el conocimiento puede ser disvalioso es una tesis que Sócrates estaría dispuesto a avalar. En el Eutidemo Sócrates sostiene la, en cierto modo, extravagante tesis de que la persona virtuosa tiene todo lo que es necesario para ser feliz: sabiduría, conocimiento, "la única cosa buena por sí misma", lo que hace que a los seres humanos siempre les vaya bien"87; las demás cosas -que en general se supone que son "bienes reales"- no son bienes a menos que estén acompañados de conocimiento, de modo que son bienes condicionales. ${ }^{88}$

Sócrates, entonces, no puede ser encasillado ni en la "opinión estándar" (la ignorancia es ausencia de conocimiento) ni en "la nueva opinión u opinión alternativa" (la ignorancia es ausencia de una creencia verdadera). Sin embargo, en la medida en que Sócrates valora cierto tipo de ignorancia en la búsqueda del conocimiento, creo que pueden establecerse conexiones interesantes entre su pensamiento y el proyecto epistemológico que pone el acento en el valor de la ignorancia que se refiere a la humildad como "virtud epistémica". Esta, entre otras, puede ser una buena razón para incorporar a Sócrates a la discusión en un sentido sistemático y no solo histórico. Esto último también vale para los demás problemas que he discutido antes en mi intento de mostrar que, al menos algunos temas y

${ }^{86}$ Que el conocimiento puede ser disvalioso en un sentido práctico, no implica que carezca de valor epistémico sin más (el ejemplo es de Duncan Pritchard, "Ignorance and Epistemic Value." En The Epistemic Dimensions of Ignorance, de Rik Peels y Martikn Blaauw (Cambridge: Cambridge University Press, 2016), 133-134).

87 Platón, Eutidemo 280a6.

88 Platón, Eutidemo 279a-281e. La misma posición es defendida, casi en los mismos términos, por el Platón tardío (puede compararse Platón, Leyes 631b3-d2, 660e2-661e4 con estos pasajes del Eutidemo y con Gorgias 507a5-c7). 
argumentos de los filósofos antiguos, mantienen su frescura e interés en la actualidad. Si lo que he argumentado es razonable, espero haber mostrado que los filósofos antiguos ofrecen un excelente punto de partida para reflexionar sobre diferentes temas filosóficos desde variadas perspectivas. La filosofía antigua puede ser una búsqueda esclarecedora en sí misma, y también una forma fascinante de entender la filosofía contemporánea. ${ }^{89}$

${ }^{89}$ Este artículo se basa en otro que publiqué hace muchos años (Marcelo Boeri, “¿Por qué ocuparse de filosofía antigua hoy?” Kléos vol.4, $\mathrm{N}^{\circ} 4$ (2000): 131-153). El presente texto es, a su vez, una versión española de Marcelo Boeri, "Why to Get involved in Ancient Philosophy Nowadays? Philosophy, History of Philosophy and Ancient Thought." En Per la rinascita di un pensiero critico contemporaneo. II. Contributo degli antichi, editado por Maurizio Migliori y Francesca Eustacchi (Milano: Mimesis, 2017). Este último texto ya contenía una importante cantidad de material nuevo respecto de la versión de 2000 . A su vez, esta última versión española que ahora presento tiene algunos desarrollos que no se encuentran en la versión inglesa de 2017. Algunas ideas de este estudio las presenté en la Université Pierre-Mendès-France, Grenoble II (Marzo de 2015), en el coloquio "L' âme dans la philosophie antique" organizado por Michel Fattal. Estoy agradecido con el Profesor Fattal por su invitación, y a él y al auditorio por sus observaciones. Agradezco a Francisco Abalo su invitación a participar de este volumen. 


\section{BIBLIOGRAFIA}

Asmis, Elizabeth. Epicurus' Scientific Method. Ithaca and London: Cornell University Press, 1984.

Boeri, Marcelo. "Theaetetus and Protarchus: two philosophical characters or what a philosophical soul should do." En Plato's Styles and Characters, de Gabriele Cornelli, 357-378. Hildescheim-Zürich-New York: Walter de Gruyter, 2016.

—. “¿Por qué ocuparse de filosofía antigua hoy?” Kléos vol.4, №4 (2000): 131-153.

-. "Why to Get involved in Ancient Philosophy Nowadays? Philosophy, History of Philosophy and Ancient Thought." En Per la rinascita di un pensiero critico contemporaneo. II. Contributo degli antichi, de Maurizio Migliori y Francesca Eustacchi, 53-70. Milano: Mimesis, 2017.

Bonjour, Laurence. Epistemology. Classic Problems and Contemporary Responses. Lanham-Boulder.New York-Toronto: Rowman \& Littlefield Publishers, 2010.

Brickhouse, Thomas, y Nicholas Smith. Socratic Moral Psychology. Cambridge: Cambridge University Press, 2010.

- The Philosophy of Socrates. Boulder, Colorado: Westview Press, 2000.

Burnyeat, Myles. "Idealism and Greek Philosophy." En Explorations in Ancient and Modern Philosophy, de Myles Burnyeat, 245-275. Cambridge: Cambridge University Press, 2012.

Clay, Diskin. Paradosis and Survival. Three Chapters in the History of Epicurean Philosophy. Ann Arbor: The University of Michigan Press, 2001.

Davidson, Donald. Subjective, Intersubjective, Objective. Oxford: Clarendon Press, 2001.

-. "First Person Authorithy." En Subjective, Intersubjective, Objective, de Donald Davidson, 3-14. Oxford: Clarendon Press, 2001.

- . "Indeterminism and Antirealism." En Subjective, Intersubjective, Objective, de Donald Davidson, 69-84. Oxford: Clarendon Press, 2001.

- . "The Irreductibility of the Concept of the Self." En Subjective, Intersubjective, Objective, de Donald Davidson, 85-91. Oxford: Clarendon Press, 2001.

—. "Rational Animals." En Subjective, Intersubjective, Objective, de Donald Davidson, 95-105. Oxford: Clarendon Press, 2001.

—. "Epistemology Externalized." En Subjective, Intersubjective, Objective, de Donald Davidson, 193-204. Oxford: Clarendon Press, 2001.

—. Problems of Rationality. Oxford: Oxford University Press, 2004.

—. "The Problem of Objectivity." En Problems of Rationality, de Donald Davidson, 3-18. Oxford: Oxford University Press, 2004.

-. "Deception and Division." En Problems of Rationality, de Donald Davidson, 199-212. Oxford: Oxford University Press, 2004. 
-. "What Thought Requires." En Problems of Rationality, de Donald Davidson, 135-149. Oxford: Oxford University Press, 2004.

—. Thruth, Language and History. Oxford: Oxford University Press, 2005.

-. "Dialectic and Dialogue." En Thruth, Language and History, de Donald Davidson, 251-259. Oxford: Oxford University Press, 2005.

- . "Plato's Philosopher." En Truth, Language and History, de Donald Davidson, 223-240. Oxford: Oxford University Press, 2005.

Ferrari, Franco. Platone. Teeteto (Introduzione, traduzione e comment di Franco Ferrari). Milano: BUR, 2001.

Goldman, Alvin, y Erik Olsson. "Reliabilism and the Value of Knowledge." En Epistemic Value, de Adrian Haddock, Alan Millar y Duncan Pritchard, 19-41. Oxford: Oxford University Press, 2009.

Jones, Ward. "The Good and Motivation of Believing." En Epistemic Value, de Adrian Haddock, Alan Millar y Duncan Pritchard, 139-162. Oxford: Oxford University Press, 2009.

Kahn, Charles. Plato and the Socratic Dialogue. The Philosophical Use of a Literary Form. Cambridge: Cambridge University Press, 1996.

Kim, Jaegwon. "What is 'naturalized epistemology'?" En Epistemology. An Anthology, de Ernest Sosa, Jaegwon Kim, Jeremy Fantl y Matthew McGrath, 538-551. Malden-Oxford-Victoria: Blackwell Publishing, 2008.

Migliori, Maurizio. Il Disordine ordinato. La filosofia dialettica di Platone I. Dialettica, metafisica e cosmologia. Brescia: Morcelliana, 2013.

Moser, Paul. "Tripartite definition of knowledge." En A Companion to Epistemology, de Jonathan Dancy, Ernest Sosa y Matthias Steup, 771-772. Oxford: Blackwell Publishing Ltda, 2010.

Napolitano, Linda. Platone e le 'ragioni' dell'immagine. Percorsi filosofici e deviazioni tra metafore e miti. Milano: Vita e Pensiere, 2007.

Nikulin, Dmitri. Dialectic and Dialogue. Stanford: Stanford University Press, 2010.

Peels, Rik, y Martikn Blaauw. "Introduction." En The Epistemic Dimensions of Ignorance, de Rik Peels y Martikn Blaauw, 1-11. Cambridge: Cambridge University Press, 2016.

Penner, Terry, y Christopher Rowe. Plato's Lysis. Cambridge: Cambridge University Press, 2015.

Pesce, Domenico. Introduzione a Epicuro. Roma-Bari: Laterza, 1980.

Pierre Le Morvan, y Rik Peels. "The Nature of Ignorance; Two Views." En The Epistemic Dimensions of Ignorance, de Rik Peels y Martikn Blaauw, 1232. Cambridge: Cambridge University Press, 2016.

Pritchard, Duncan. "Ignorance and Epistemic Value." En The Epistemic Dimensions of Ignorance, de Rik Peels y Martikn Blaauw, 132-143. Cambridge: Cambridge University Press, 2016. 
Ryle, Gilbert. The Concept of Mind. London and New York: Routledge, 2009 ( Primera edición publicada originalmente en 1949).

Shope, Robert. "Propositional Knowledge." En A Companion to Epistemology, de Jonathan Dancy, Ernest Sosa y Matthias Steup, 644-648. Oxford: Blackwell Publishing Ltda, 2010.

Weiner, Matthew. "Practical Reasoning and the Concept of Knowledge." En Epistemic Value, de Adrian Haddock, Alan Millar y Duncan Pritchard, 163-182. Oxford: Oxford University Press, 2009.

Wieland, Wolfgang. "La actualidad de la filosofía antigua." Traducido por Alejandro Vigo. Méthexis vol.1 N¹ (1988): 3-16.

Williamson, Timothy. Knowledge and its Limits. Oxford: Oxford University Press, 2000.

Zarka, Yves. "The Ideology of Context: Uses and Abuses of Context in the Historiography of Philosophy." En Analytic Philosophy and History of Philosophy, de Tom Sorell y G.A.J. Rogers, 147-159. Oxford: Oxford University Press, 2005. 